\title{
Differentially Expressed Genes during Flowering and Grain Filling in Common Bean (Phaseolus vulgaris) Grown under Drought Stress Conditions
}

\author{
Bárbara Salomão de Faria Müller • Tetsu Sakamoto • Ricardo Diógenes Dias Silveira • \\ Patricia Fernanda Zambussi-Carvalho • Maristela Pereira • Georgios Joanis Pappas Jr • \\ Marcos Mota do Carmo Costa • Cleber Moraes Guimarães • Wendell Jacinto Pereira • \\ Claudio Brondani • Rosana Pereira Vianello-Brondani
}

Published online: 2 October 2013

(C) Springer Science+Business Media New York 2013

\begin{abstract}
Drought stress, particularly during the flowering and grain-filling stages of growth, contributes to serious yield loss in common bean (Phaseolus vulgaris L.). The aim of this study was to identify genes induced in response to drought stress using transcriptome analysis of contrasting genotypes. Using leaf tissues of tolerant (BAT 477) and susceptible common bean genotypes (Pérola), collected at the flowering and grain-filling stages, four complementary deoxyribonucleic acid representational difference analysis subtractive libraries were constructed and then sequenced. A total of 7,203 (77.6\%) sequences with an average sequence size of $570 \mathrm{bp}$ were considered valid, for a combined $4 \mathrm{Mbp}$ sequence. According to a differential display analysis, 802 expressed sequence tags, distributed across 67 contigs, were differentially expressed by the tolerant (37 contigs) and susceptible
\end{abstract}

Electronic supplementary material The online version of this article (doi:10.1007/s11105-013-0651-7) contains supplementary material, which is available to authorized users.

\section{B. S. F. Müller}

Plant Molecular Genetics Laboratory, Institute of Biotechnology

Applied to Agriculture and Animal Science (BIOAGRO),

Federal University of Viçosa, Viçosa, MG 36570-000, Brazil

\section{T. Sakamoto}

BioData Laboratory, Institute of Biological Science, Federal University of Minas Gerais, Belo Horizonte, MG 31270-901, Brazil

B. S. F. Müller • R. D. D. Silveira • W. J. Pereira • C. Brondani •

R. P. Vianello-Brondani $(\triangle)$

Biotechnology Laboratory, Embrapa Rice and Beans, Santo Antônio

de Goiás, GO 75375-000, Brazil

e-mail: rosana.vianello@embrapa.br genotypes (30 contigs) after identification under drought conditions during the two investigated plant developmental stages. Of these differential contigs, the 13 most frequent genes were exclusive to the tolerant genotype. Based on BLAST2GO, $73 \%$ of the gene sequences were annotated and $12 \%$ showed mapping results, with the highest similarity rate corresponding to Glycine $\max (41 \%)$. According to gene ontology functional analysis, $48 \%$ of the sequences were attributed to cell metabolic processes. Overall, $8.3 \%$ of the transcribed sequences exhibited similarity to transcription factors, predominantly those of the AP2-EREBP family $(97.8 \%)$. Of the target sequences validated by quantitative real-time polymerase chain reaction, most genes showed an expression level that agreed with that predicted by in silico analysis. Thus, the drought transcriptome dataset is a valuable

\section{P. F. Zambussi-Carvalho • M. Pereira}

Molecular Biology Laboratory, Department of Biochemistry and

Molecular Biology, Institute of Biological Science, Federal

University of Goiás, Goiânia, GO 74001-970, Brazil

\section{G. J. Pappas Jr}

Laboratory of Molecular Biology, Department of Cellular Biology,

University of Brasília, Brasília, DF 70790-160, Brazil

M. M. do Carmo Costa

Bioinformatics Laboratory, Embrapa Genetic Resources and

Biotechnology, Brasília, DF 70770-901, Brazil

C. M. Guimarães

Agrophysiology Laboratory, Embrapa Rice and Beans, Santo

Antônio de Goiás, GO 75375-000, Brazil 
resource on the variation in these gene sequences, offering the opportunity to identify robust molecular markers tightly linked to trait-controlling loci for use in marker-assisted breeding.

Keywords Legume crop - Abiotic stress - ESTs sequencing · Drought stress

\section{Introduction}

Drought is one of the main climatic factors that affect agriculture worldwide, and it is further aggravated by population growth and the consequent increase in food demand, especially in developing countries (FAO 2012). Extreme temperatures and rainfall indices exert direct effects on the development of leguminous plants, which are quite demanding with regard to the climate conditions (Lacerda et al. 2010). Extreme temperature and rainfall represent an important factor associated with reduced Phaseolus vulgaris (common bean) yields; exacerbated by disease (Beebe et al. 2013). Data from the Food and Agriculture Organization (FAO) estimate that the average global common bean yield was approximately 21 million tons in the past 5 years, and 6.7 million tons $(27 \%)$ were produced in Latin America. The common bean is mostly grown in drought-prone areas, which might lead to losses as high as $80 \%$ of the production in Africa, Mexico, and Brazil (Emam et al. 2010; Rosales et al. 2012b). The common bean is particularly susceptible to drought, especially during the flowering and grain-filling stages (Nunez-Barrios 1991; Fageria et al. 1991). Appropriate handling techniques and the identification and/or development of more drought-resistant genotypes are considered efficacious techniques to minimize the negative effects of drought on common bean yields (Asfaw 2011).

As drought tolerance is polygenic and involves mechanisms that act alone or in combination, it is considered a complex trait that is difficult to genetically modify and understand (Rabello et al. 2008). As a consequence, plants have developed morphologic, physiologic, cellular, and metabolic adaptive strategies for survival and reproduction (Atkinson and Urwin 2012). The identification of differentially expressed genes under water-deficit conditions is an attractive strategy to dissect stress response mechanisms (Bray 1993; Kavar et al. 2008). At the transcriptional level, expressed sequence tag (EST) sequencing has been widely used to discover and identify genes potentially involved in drought response (Kakumanu et al. 2012). Among other transcriptome profiling methods, representational difference analysis (RDA, Lisitsyn et al. 1993), serial analysis of gene expression (SAGE, Velculescu et al. 1995), deoxyribonucleic acid (DNA) microarrays (Schena et al. 1995), and suppression subtractive hybridization (SSH, Diatchenko et al. 1996) are commonly used, as is the recently developed ribonucleic acid (RNA)-Seq strategy, which is based on massive RNA sequencing by means of nextgeneration sequencing (Nagalakshmi et al. 2010). The differentially regulated genes under different stress conditions could be used to reconstruct responsive pathways, predict sites of action, and identify new associated genes (Prabu et al. 2011; Le et al. 2012).

With the establishment of projects to sequence ESTs, a large amount of DNA sequence information has been generated and deposited in public databases. Currently, 6,292,093 Leguminosae nucleotide sequences are deposited at GenBank, and approximately $53 \%$ of these sequences are EST products $(3,310,689)$. The majority of these ESTs are derived from Glycine max (44\%), followed by Phaseolus coccineus (12\%), Medicago truncatula (8\%), Lotus japonicus (7.3\%), Vigna unguiculata (5.7\%), Arachis hypogaea (5.4\%), P. vulgaris $(3.8 \%)$, and other species (13.8\%). The open access sequence information promotes the common bean as a model leguminous plant (McClean et al. 2010; Kalavacharla et al. 2011).

Genome information from $P$. vulgaris plants subjected to abiotic stress has been gradually produced by several research groups. EST collections are becoming publicly available and include genes that are positively or negatively regulated under conditions of stress such as phosphorus deficiency (Graham et al. 2005; Tian et al. 2007; Blair et al. 2011a). More recently, a study conducted by Blair et al. (2011b) assessed the Andean (G19833) and Mesoamerican (BAT 477) genotypes under drought conditions and consequently identified and annotated 4,219 unigenes that consisted of 2,981 contigs and 1,238 singlets. Globally, the relevance and strategic value of the identification of genes that can confer greater drought tolerance in common bean have increased. To contribute to the understanding of the genetic mechanisms involved in drought tolerance, the main aims of the present study were to analyze the common bean transcriptome of drought tolerance in contrasting genotypes at two critical stages of plant development (flowering and grain filling) and to subsequently identify the differentially expressed genes and contribute to a database of ESTs that are potentially involved in drought response.

\section{Materials and Methods}

\section{Plant Material}

The $P$. vulgaris genotypes that differed in terms of performance under drought conditions were the lineages BAT 477, characterized as drought-resistant (Miklas et al. 2006), and the Pérola cultivar, which is drought-sensitive (Guimarães et al. 2002). BAT 477 is a lineage derived from the genetic improvement program at the International Center for Tropical Agriculture (CIAT, Colombia). Pérola was developed at the Empresa Brasileira de Pesquisa Agropecuária (EMBRAPA) 
genetic improvement program in 1994 (Brazil). Both lineages belong to the Mesoamerican gene pool and present growth habit type III (Terán and Singh 2002; Gonçalves et al. 2009).

\section{Drought Stress Treatment}

The soil was superficially fertilized before sowing with a 5:30:15 mixture of N:P:K $\left(400 \mathrm{~kg} \mathrm{ha}^{-1}\right)$. Common bean seeds were sown inside polyvinyl chloride columns that contained approximately $48 \mathrm{~kg}$ of native Cerrado (Brazilian savanna) soil and were kept in a screen house. All plants were irrigated in a regular manner before the onset of the first stress period. The control plants, which were also of the BAT 477 and Pérola genotypes, were irrigated in a regular manner throughout the development cycle. Drought exposure was achieved by subjecting an independent group of plants to water restriction over 7 days during the (1) preflowering (31 days after sowing) and (2) grain-filling (46 days after sowing) reproductive stages. During these two reproductive stages of water stress, three irrigation regimes were used: group A (control samples): full water supply during the complete growing season based on the measurement of soil moisture with a tensiometer (minimum soil humidity of $-0.025 \mathrm{MPa}$ at 15 $\mathrm{cm}$ depth); group B: $50 \%$ water supply at the preflowering time; and group C: $50 \%$ water supply at the grain-filling time. Detailed information was provided by Morais Júnior et al. (2008). For the collection of well-watered and drought-treated leaves at the flowering and grain-filling reproductive stages, the hydric status was evaluated by the measuring the tissue water potential and leaf temperature from 7 a.m. to 6 p.m. The leaf water potential $\left(\Psi_{\mathrm{f}}\right)$ and the canopy temperature $\left(T_{\mathrm{f}}\right)$ were evaluated to infer the plant water content. Because both lineages presented the same physiological growth type III, with the flowering and grain filling occurring in the same period of time, the drought-stressed plants were harvested (in three biological replicates) at the same time after sowing (same physiological growth stage), immediately frozen in liquid nitrogen and stored at $-80^{\circ} \mathrm{C}$ before RNA isolation.

\section{RNA Extraction and Construction of cDNA Subtractive Libraries}

Total RNA was extracted from the foliar tissue samples of adult plants. The tissue samples were immediately frozen in liquid nitrogen and stored at $-80{ }^{\circ} \mathrm{C}$. RNA was extracted with the strong denaturing agents phenol and guanidine salts as previously described (Chomczynski and Sacchi 1987). Finally, the total RNA was resuspended in RNase-free water and stored at $-80{ }^{\circ} \mathrm{C}$. Quantitative and qualitative assessments were performed with a spectrophotometer and $1 \%$ denaturing agarose gels in RNase-free Tris acetate-EDTA (TAE) buffer, respectively.
Development of the Subtractive Libraries

Messenger RNA was isolated from total RNA and used to construct the complementary DNA (cDNA) subtraction libraries according to the RDA technique (Lisitsyn et al. 1993). The RDA technique was based on subtractive hybridization, as described by Pastorian et al. (2000), with modifications. A total of eight cDNA libraries were constructed, and the subtraction was performed between the genotypes subjected to drought vs. the same genotype well-watered, resulting in four RDA libraries. The RDA technique included hybridization of a tester cDNA sample (BAT 477 or Pérola subjected to drought) and a driver cDNA sample in large excess (BAT 477 or Pérola not subjected to drought; control samples), such that the cDNA fragments from the drought-subjected BAT 477 or Pérola hybridized to the fragments from the control BAT 477 or Pérola, respectively. Tester cDNAs linked to adapters were subjected to two successive cycles of subtraction and amplification by polymerase chain reaction (PCR) of tester/driver hybridizations at 1:10 and 1:100 ratios, followed by purification with the GFX kit (GE Healthcare, Chalfont St. Giles, UK). Next, the tester cDNAs were directly cloned into the $p G E M-T$ Easy vector (Promega, Madison, WI, USA), followed by transformation into Escherichia coli XL1-Blue competent cells by electroporation. Finally, four cDNA subtraction libraries were developed that corresponded to the BAT 477 genotypes in the flowering (RDA-BAT $477 \mathrm{~F}$ ) and grain-filling (RDA-BAT 477 GF) stages and the Pérola genotypes in the flowering (RDA-Pérola F) and grain-filling (RDA-Pérola GF) stages.

\section{DNA Sequencing}

Plasmid DNA was isolated from the transformed bacteria by alkaline lysis as described by Brondani et al. (2007), with modifications. The amplification reaction used to sequence the cloned DNA included $0.4 \mu \mathrm{M}$ primer T7 $(2.0 \mu \mathrm{M}), 2 \mu \mathrm{g}$ of plasmid DNA 1, 1.5 $\times$ DYEnamic $^{\text {TM }}$ ET dye terminator cycle sequencing kit (GE Healthcare), and Milli-Q sterile water for a final volume of $10 \mu \mathrm{l}$. The amplifications were performed in a GeneAmp PCR System 9700 thermocycler (Applied Biosystems, Foster City, CA, USA) as follows: 25 cycles at $96{ }^{\circ} \mathrm{C}$ for $20 \mathrm{~s}, 50{ }^{\circ} \mathrm{C}$ for $15 \mathrm{~s}$, and $60^{\circ} \mathrm{C}$ for $1 \mathrm{~min}$. Following amplification, the products were purified according to the manufacturer's instructions (Applied Biosystems), followed by the addition of $10 \mu \mathrm{l}$ of Hi-DI ${ }^{\circledR}$ formamide (Applied Biosystems) and denaturation at $95{ }^{\circ} \mathrm{C}$ for $5 \mathrm{~min}$. Sequencing was performed on an ABI 3100 automatic analyzer (Applied Biosystems).

\section{EST Processing}

The data were collected with the Foundation Data Collection software package (Applied Biosystems), and the sequences 
were processed with Sequencing Analysis 5.1 software (Applied Biosystems). The sequencing reads were analyzed using the SisGen genome annotation system (Pappas et al. 2008). Base calling was carried out using Phred (Ewing et al. 1998), and sequence preprocessing included vector masking and quality trimming to remove low-quality sequence ends (average error probability $=1 \%$ in a 15 -base window). EST clustering was performed by a TIGR gene indices clustering tool (Pertea et al. 2003). The Venn diagram was generated with the Venny tool (http://bioinfogp.cnb.csic.es/tools/venny/index.html).

\section{Functional Annotation}

Differential display (DD) analysis was performed for the in silico identification of genes that were differentially expressed by the contrasting drought tolerance genotypes at the same stages of plant development. In the present study, contigs were defined as exclusive when composed of five or more differentially expressed ESTs in a genotype.

The ESTs were annotated according to the BLAST suite (Altschul et al. 1997) and compared to the database of nonredundant proteins with the standard configurations. The BLAST2GO tool (Conesa et al. 2005), using default settings ( $E$-value $<1 \mathrm{E}-06$, annotation cutoff $=55)$, was used to functionally categorize the ESTs in terms of gene ontology (GO) categories.

To identify the ESTs corresponding to transcription factors (TFs), the generated sequences were mapped by aligning the sequences exclusively against the $P$. vulgaris Mesoamerican variety reference genome (http://mazorka.langebio.cinvestav. $\mathrm{mx} / \mathrm{phaseolus} /)$ via the BLASTn algorithm ( $E$-value $<1 \mathrm{E}-03)$. To identify the TFs, the alignment hits were compared with the Plant TF database (PlnTFDB; http://plntfdb.bio.uni-potsdam.de/ v3.0/; Pérez-Rodríguez et al. 2010).

\section{Validation of the Differentially Expressed Genes by qPCR}

To perform validation with quantitative real-time PCR (qPCR), four candidate genes were selected due to their differential overexpression profiles (number of copies per cluster), of which three were more abundantly expressed by the tolerant genotype BAT 477 and one by the susceptible genotype Pérola (Additional File 1). EST alignment of the clusters containing the same identified target genes in more than one contig was performed with ClustalW software (Thompson et al. 1994), and the consensus sequences were generated. TaqMan probes were developed with the Custom TaqMan ${ }^{\circledR}$ genomic assays service and File Builder software (Applied Biosystems).

For qPCR genetic expression analysis, the 12 tested cDNA samples were taken from a drought experiment (Additional File 2) that was conducted according to Martins et al. (2008).
All tests were performed in triplicate with standard qPCR reagents (TaqMan Universal PCR Master Mix, Applied Biosystems) and the primers and probes specific for each gene. Elongation factor (assay ID AI20SMX) and 18S ribosomal RNA (assay ID AI39QS5) were used as reference genes. Amplifications and readings were performed with the Applied Biosystems ${ }^{\circledR} 7500$ real-time PCR system device (Applied Biosystems), followed by analysis with Sequence Detection software (SDS) v.1.3 (Applied Biosystems). The values, expressed as the cycle threshold (CT), were subjected to Tukey's test $(p=0.05)$ with Statistica 7.0 software (StatSoft, Tulsa, OK, USA) and to the CT-comparative method with DataAssist 3.01 software (Applied Biosystems). The reference gene stability was assessed with the geNorm Plus application ( $M$ values) integrated into the qbase $\mathrm{e}^{\mathrm{PLUS}} / \mathrm{qPCR}$ data analysis software package (Hellemans et al. 2007).

\section{Results}

Sequencing of the Common Bean Transcriptome

The BAT 477 genotype of Mesoamerican bean gene pool has been successfully used in breeding programs for drought resistance (Beebe et al. 2013), and in the current study, the lower values of $\Psi_{\mathrm{f}}$ and $T_{\mathrm{f}}$ presented under drought conditions demonstrated the physiological state contrasting with the Pérola genotype. From the four cDNA-RDA subtraction libraries that we developed for $P$. vulgaris under drought conditions at different stages of plant development, a total of 9,273 sequences were obtained via Sanger sequencing. After these were subjected to a bioinformatic quality control pipeline, 7,203 (77.6\%) sequences, with an average length of $570 \mathrm{bp}$, were considered for further analyses. The sequencing results of the four cDNA-RDA libraries were individually analyzed to obtain estimates for each assessed condition (Table 1). The total number of valid fragments $(7,203)$ varied from a maximum of 2,270 in the BAT 477 Pérola F library to a minimum of 1,434 in the Pérola GF library.

The valid sequence reads were clustered generating 3,066 unigenes, which included 439 contigs (4,576 reads) and 2,627 singlets. Based on the sequence clusters, it was possible to compare the EST contribution of tolerant and susceptible genotypes under drought conditions. Of the 2,666 ESTs from plants in the flowering stage under drought conditions, $1,431(53.67 \%)$ were exclusive to the susceptible genotype Pérola, $623(23.36 \%)$ to the tolerant genotype BAT 477, and $306(11.47 \%)$ shared by both. In the grainfilling stage, a total of 1,910 sequences were assessed; 546 $(28.58 \%)$ were exclusive to the Pérola GF library, 522 $(27.33 \%)$ to the BAT 477 GF library, and 421 (22.04\%) common to both genotypes (Fig. 1a and b). 
Table 1 Numbers of redundant and unique sequences and numbers of contigs and singletons that were generated from the four Phaseolus vulgaris cDNA-RDA subtraction libraries

\begin{tabular}{llllll}
\hline Libraries ID & Sequenced fragments & Valid fragments & Contigs & Singlets & Total of unigenes \\
\hline Pérola GF & 3056 & 2270 & $118(1737)$ & 533 & 651 \\
BAT477 GF & 2377 & 1820 & $133(929)$ & 891 & 1024 \\
Pérola F & 1632 & 1434 & $98(967)$ & 467 & 565 \\
BAT477 F & 2208 & 1679 & $90(943)$ & 736 & 826 \\
Total & 9273 & 7203 & $439(4576)$ & 2627 & 3066 \\
\hline
\end{tabular}

\section{DD Analysis}

Electronic DD analysis was performed to identify differentially expressed sequences between the tolerant (BAT 477) and susceptible (Pérola) genotypes. The sequences derived from the four RDA-libraries were compared between the groups RDABAT 477_GF and RDA-Perola_GF and between RDA-BAT 477 F and RDA-Perola_F. Following a DD analysis of the total set of validated sequences, 136 exclusive contigs and 155 exclusive singlets were identified and characterized as differentially expressed in at least one of the four RDA libraries. The contigs that exhibited similarity with sequences from non-plant organisms were excluded from the analysis (30 contigs), and the remaining contigs were analyzed for redundancy. Redundant contigs were defined as those similar to the same putative protein that was associated with the same species and database accession. Redundant contigs (39) were identified and excluded, resulting in 67 unique contigs available for detailed analyses of the exclusive sequences. After in silico subtraction analysis, the contigs composed of ESTs from only one library were characterized by origin and developmental stage.

A set of 802 ESTs included in the above mentioned 67 contigs were subjected to in silico subtraction analysis relative to the differentially expressed sequences in the droughttolerant (BAT 477) and drought-susceptible genotypes (Pérola) during the flowering and grain-filling developmental stages (Additional File 3). The ESTs were considered exclusive when the redundancy relative to the same gene transcribed in another subtraction library was at least fivefold higher. Based on this criterion, 30 contigs from the
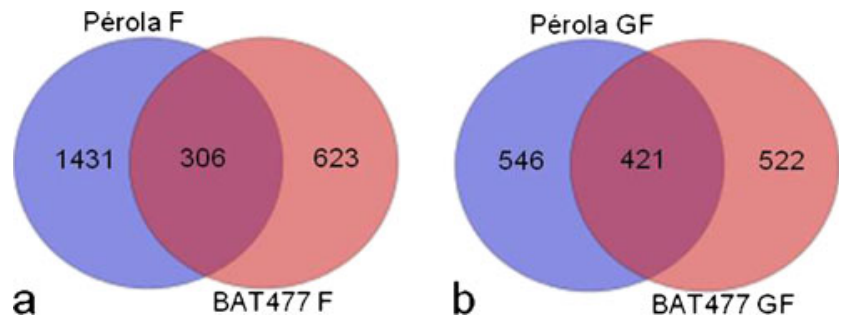

Fig. 1 Venn diagram representing the number of unigenes compared among the subtraction libraries. a Susceptible (Pérola F) and tolerant genotype (BAT $477 \mathrm{~F}$ ) libraries compared at the flowering $(F)$ stage. b Pérola GF and BAT 477 GF libraries compared at the grain filling $(G F)$ stage susceptible and 37 contigs from the tolerant genotype were identified. Of the 30 differentially expressed genes in the susceptible genotype, 22 were identified during the flowering stage and 8 in the grain-filling stage, and 12 were exclusive contigs. Of the 37 differentially expressed contigs in the tolerant genotype, 20 were identified in the flowering stage and 17 in the grain-filling stage, and 13 were exclusive (Table 2).

\section{Functional Annotation}

The sequences constituting the contigs were subjected to a BLAST similarity search against the nonredundant GenBank database. Of the 67 differentially expressed sequences, 37 (55\%) contigs from the tolerant genotype were successfully annotated and exhibited similarity with sequences that were previously described as related to biotic and abiotic stress (Additional File 3). Among the identified genes, those involved in responses to drought and oxidative stress included the zinc finger $\mathrm{C} 2 \mathrm{H} 2$ family, protein kinases, chaperones, auxin-repressed protein (ARP), ubiquitin-conjugating enzyme (E2), ubiquinone oxidoreductase, isocitrate dehydrogenase, calmodulin-like protein, and hypersensitive-induced response (HIR) protein. Genes related to components of photosystem II (PSII), such as chlorophyll $a / b$-binding protein, were also identified.

From a total of 4,576 ESTs, $73 \%$ were annotated, $12 \%$ exhibited mapping results, $12 \%$ had BLAST results but failed to be mapped and annotated, and $3 \%$ showed no BLASTx hits ( $E$ values ranging from $1 \mathrm{E}-04$ to $1 \mathrm{E}-107)$. With regard to similarities with database sequences (BLAST "Top-Hits"), the greatest similarity was to $G$. $\max (41 \%)$, followed by $M$. truncatula (15\%), Oryza sativa (6\%), and only $1.5 \%$ to $P$. vulgaris (Supplementary Fig. 1). Alignments of these same 4,576 ESTs against the $P$. vulgaris reference genome identified 3,823 ESTs $(83.5 \%)$ with similar sequences, of which $318(8.3 \%)$ corresponded to TFs. The AP2-EREBP TF family predominated $(97.8 \%)$, followed by the DBP $(2 \%)$ and CCAAT $(0.3 \%)$ families.

GO categorization, as provided by BLAST2GO, is shown in Supplementary Fig. 2 and Additional File 4. The most representative distributions in the biological process category (Fig. 2a) were as follows: cellular metabolic process $(2,204$ gene or sequence products), primary metabolic process 
Table 2 Description of the 13 exclusive contigs (EST redundancy $\geq 5 \times$ ) identified in the BAT 477 (tolerant) genotype during the flowering and grain filling stages, including contig identification, derived genetic products from the GenBank database, species with the highest similarity estimates and corresponding $E$ values, and the number of times the EST was sampled

\begin{tabular}{|c|c|c|c|c|}
\hline Contigs annotated & Genic product & Species/GI number & $E$ value & $\begin{array}{l}\text { Number } \\
\text { of reads }{ }^{\mathrm{a}}\end{array}$ \\
\hline \multicolumn{5}{|c|}{ BAT 477-flowering } \\
\hline CL38Contig1 & Uncharacterized protein LOC100305788 & Glycine $\max / 351721030$ & $3 \mathrm{E}-32$ & 5 \\
\hline CL34Contig1 & Oxygen-evolving enhancer protein & Medicago truncatula/358344003 & $2 \mathrm{E}-60$ & 6 \\
\hline CL21Contig1 & Chlorophyll $a / b$ binding protein type II & G. $\max / 16805332$ & $5 \mathrm{E}-65$ & 14 \\
\hline CL14Contig1 & Hypersensitive induced reaction protein 1 & G. $\max / 354683205$ & $6 \mathrm{E}-55$ & 21 \\
\hline CL1Contig127 & Invertase/pectin methylesterase inhibitor family protein & Arabidopsis lyrata/297310623 & $2 \mathrm{E}-06$ & 23 \\
\hline CL1Contig128 & Auxin-repressed protein & M. truncatula/357446689 & $2 \mathrm{E}-22$ & 26 \\
\hline CL1Contig125 & Predicted: 40S ribosomal protein S17-4 & G. $\max / 356521554$ & $4 \mathrm{E}-44$ & 37 \\
\hline \multicolumn{5}{|c|}{ BAT 477-grain filling } \\
\hline CL1Contig58 & Predicted: 40S ribosomal protein S16-like & G. $\max / 356524632$ & $9 \mathrm{E}-35$ & 28 \\
\hline CL1Contig60 & Leucine zipper protein & M. truncatula/357491217 & $2 \mathrm{E}-24$ & 22 \\
\hline CL1Contig64 & Unknown & Lotus japonicus/388517649 & $3 \mathrm{E}-34$ & 15 \\
\hline CL1Contig75 & Predicted: cell wall/vacuolar inhibitor of fructosidase 1-like & Cicer arietinum $/ 502150782$ & $3 \mathrm{E}-13$ & 8 \\
\hline CL1Contig80 & NAD-dependent isocitrate dehydrogenase & Nicotiana tabacum $/ 3790188$ & $3 \mathrm{E}-37$ & 12 \\
\hline CL28Contig1 & Predicted: RING-H2 finger protein ATL66-like & G. $\max / 356539989$ & $2 \mathrm{E}-34$ & 9 \\
\hline
\end{tabular}

${ }^{\text {a }}$ The number of differentially expressed EST's composing each contig, in which identical sequences of ESTs with redundancy $\geq 5 \times$ are equivalent to a unique contig

$(1,997)$, biosynthetic process $(1,272)$, macromolecule metabolic process $(1,209)$, and regulation of biological processes $(1,057)$. In the flowering stage among the 20 more abundant subcategories, the genes related to biosynthetic process, gene expression and translation were more represented in the tolerant genotype. In the grain-filling stage, the highlighted, also in the tolerant, were biosynthetic process (cellular and macromolecule), metabolic process (cellular, macromolecule and carbohydrate), secondary metabolic process, generation of precursor metabolites and energy, response to stress and endogenous stimulus, and gene expression and translation.

The main distributions in the molecular function category (Fig. 2b) were hydrolase activity $(1,197)$, ion binding $(1,041)$, small molecule binding (797), tetrapyrrole binding (609), and transferase activity (440). In the flowering stage, the subcategories with the highest representation in the tolerant were RNA binding, enzyme regulator activity, structural molecule activity, and hydrolase activity, while in the grain-filling stage the predominated nucleotide binding, structural molecule activity, and enzymatic regulatory activity. In the cell component category (Fig. 2c), the distributions were cell part $(2,574)$, membrane-bounded organelle $(1,476)$, protein complex $(1,207)$, membrane part (819), and organelle part (682). Additional File 4 details the numbers of representative genes in each functional category per library. Among the 28 subcategories represented in the flowering stage, most of them were, at least, twice more abundant in the susceptible genotype compared to the tolerant. In the tolerant genotype, the most abundant were subcategories nonmembrane-bounded organelles, ribonucleoprotein complex, cytosol, mitochondrion, and endoplasmic reticulum. During the grain filling, ribonucleoprotein complex were more represented, followed by cytoplasmic part, cell periphery, external encapsulating structure, cell wall, plastid, and thylakoid.

\section{Validation of the Differentially Expressed Genes by qPCR}

The reference genes $18 S$ and EFla were used for normalization of qPCR data, and accordingly, no significant expression differences were found in these genes $(p<0.05)$ between the assessed genotypes; the estimated combined stability was 0.003. A total of four genes were analyzed by qPCR including three genes with a higher and one with a lower expression level in tolerant genotype vs. control conditions (Additional File 1), followed by the statistical analysis of the relative quantification (RQ) values (Additional File 5). The gene encoding an oxidative stress-responsive protein (NAD-dependent isocitrate dehydrogenase; Fig. 3, panel D) was upregulated in the tolerant genotype under the treatments of dehydration (T25 and T150) compared to the tolerant and susceptible genotypes without stress. As expected, this gene was significantly downregulated in the susceptible genotype under the same treatment conditions in the foliar tissue. The expression of this gene in leaves of the tolerant genotype under stress increased 3.15-fold compared to the susceptible genotype without stress. For the chlorophyll $a / b$-binding CP29 gene (Fig. 3, panel C), an 
biological_process Level 3

a

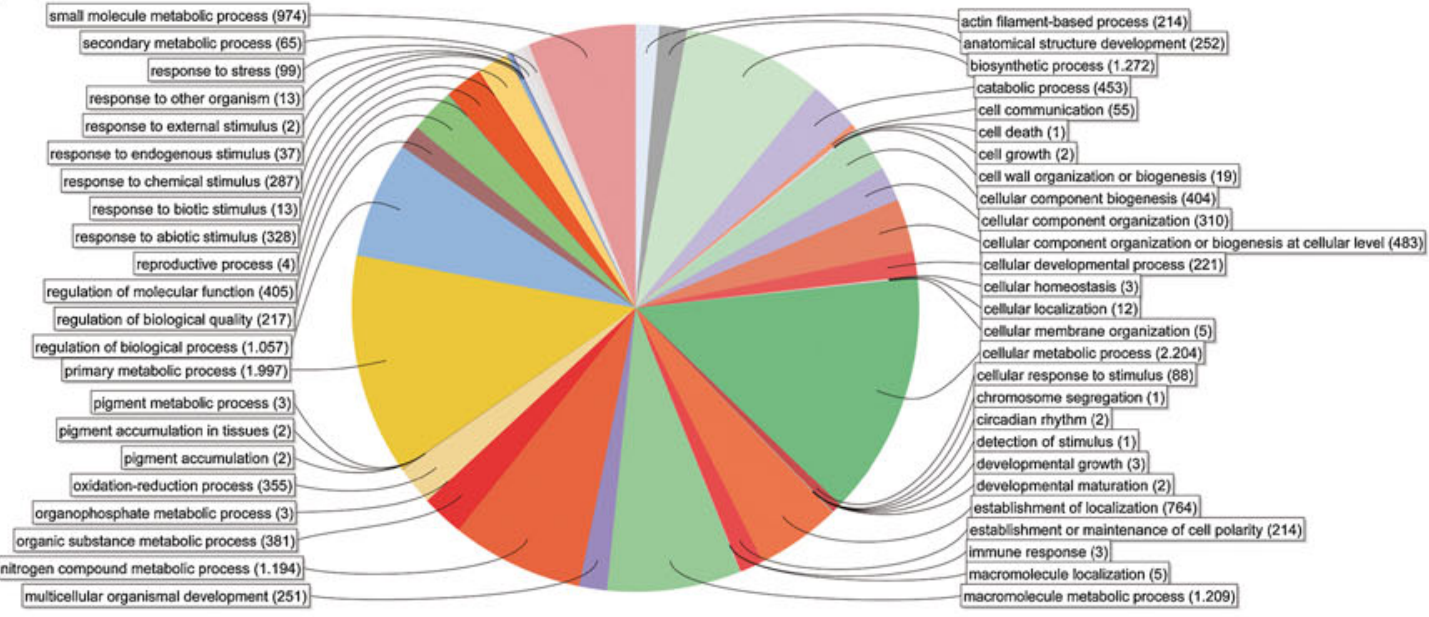

b

molecular_function Level 3

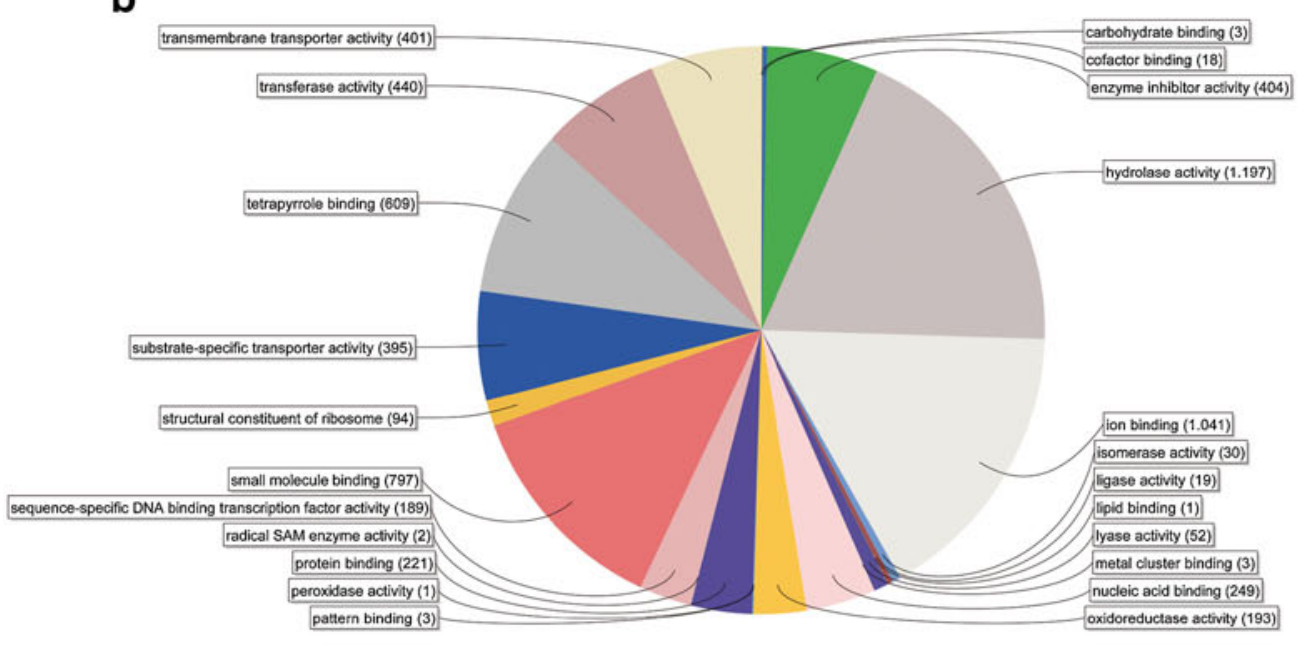

cellular_component Level 3

c

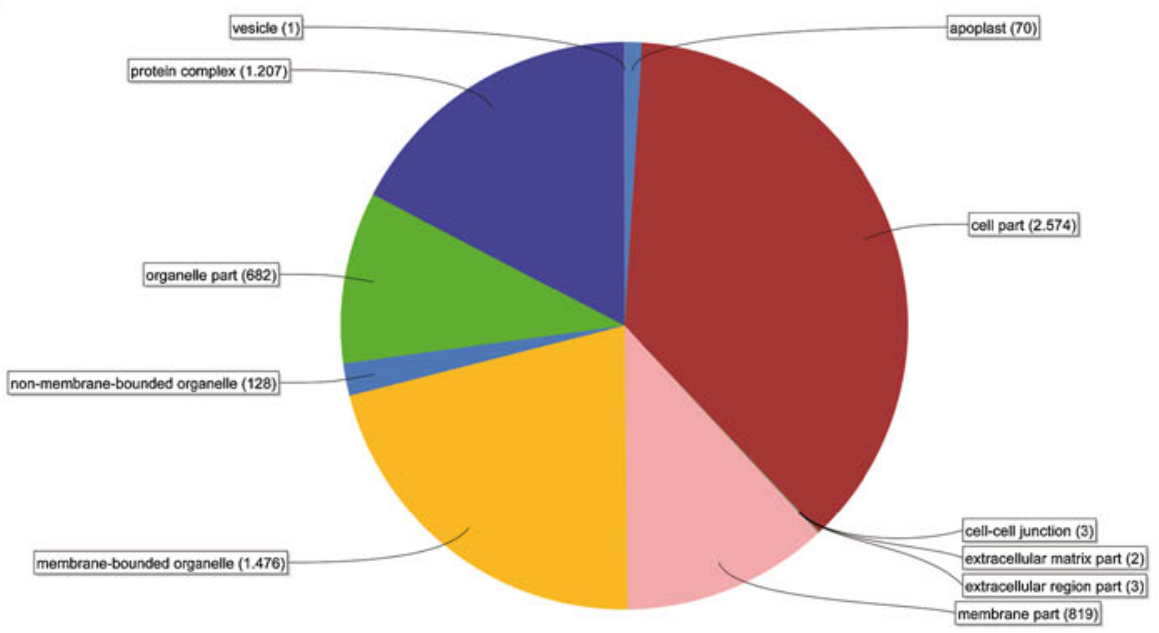


Fig. 2 Functional classification of the 4,576 unigenes derived from $P$. vulgaris according to annotation with GO terms including attributions of biological process (a), molecular function (b), and cell component (c)

interesting expression profile was observed: under the control condition, the tolerant genotype had higher expression, and under the dehydration condition (T25 and T150), its expression decreased but was higher compared to the susceptible genotype under the same stresses conditions suggesting activation of this gene under drought stress. Expression significantly increased of the ARP (Fig. 3, panel B) was observed in leaves under drought (150) in both genotypes compared to the intermediate (T25) and control conditions. In relation to leaves, high levels of expression were detected in root tissues in the absence of drought stress in both susceptible and tolerant genotypes, followed by an increase in gene expression also in both genotypes under hydric stress (data not shown). The responsive TF DREB gene was upregulated in the susceptible Pérola genotype under the maximum drought condition (23fold) vs. the susceptible genotype under the same conditions (12-fold), as observed from the transcriptional analysis (Fig. 3, panel A).
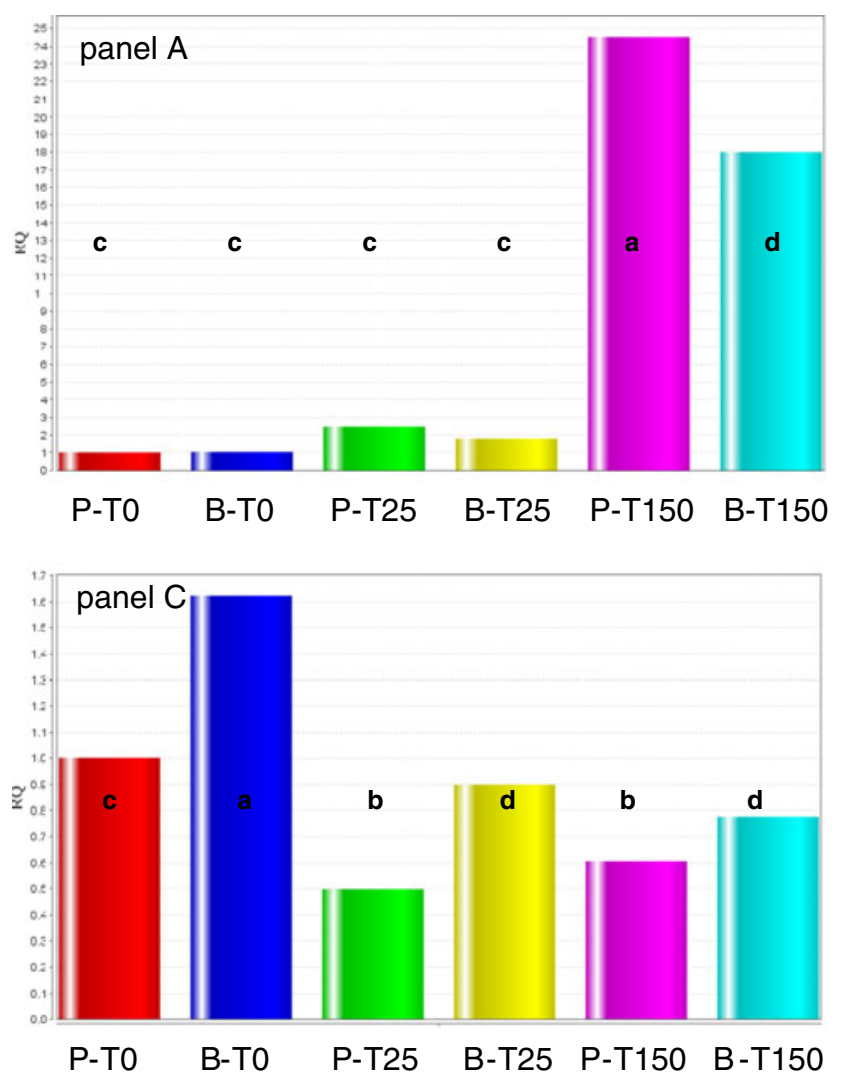

Fig. 3 Verification of "Dehydration responsive element binding protein" (panel A), 'Auxin-repressed protein" (panel B), "Chlorophyll a/b binding protein CP29" (panel $C$ ) and "NAD-dependent isocitrate dehydrogenase" (panel $D$ ) genes by qPCR in leaf tissues. The columns are organized according to the order: Pérola under control $(P-T 0)$, BAT477 under

\section{Discussion}

Drought is the main environmental stress factor that affects the growth and development of cultivated plants, and this effect is aggravated by global warming, water shortages, demographic growth, and environmental degradation (Harb et al. 2010). The impact of drought is determined by the severity of stress and the ability of plants to adapt to this stress, which is determined by physiological, biochemical, and molecular process (Rosales et al. 2012a). Because plants are susceptible to various forms of water stress, researchers have used experimental conditions ranging from moderate water stress over the full plant cycle (Blair et al. 2011b) to severe stress over short periods of time (Lizana et al. 2006). Although some losses are due to intermittent drought during the vegetative phase (Serraj et al. 2004), terminal drought is considered a major problem for common bean production because it occurs during the reproductive stage, which ranges from the preflowering to pod maturation, and affects seed yield, potentially resulting in entire crop losses (Szilagyi 2003; Rosales et al. 2012a). According to Guimarães et al. (1988) and Fageria et al. (1991), the flowering stage is most vulnerable to drought, so the expression of genes related drought response must be greater
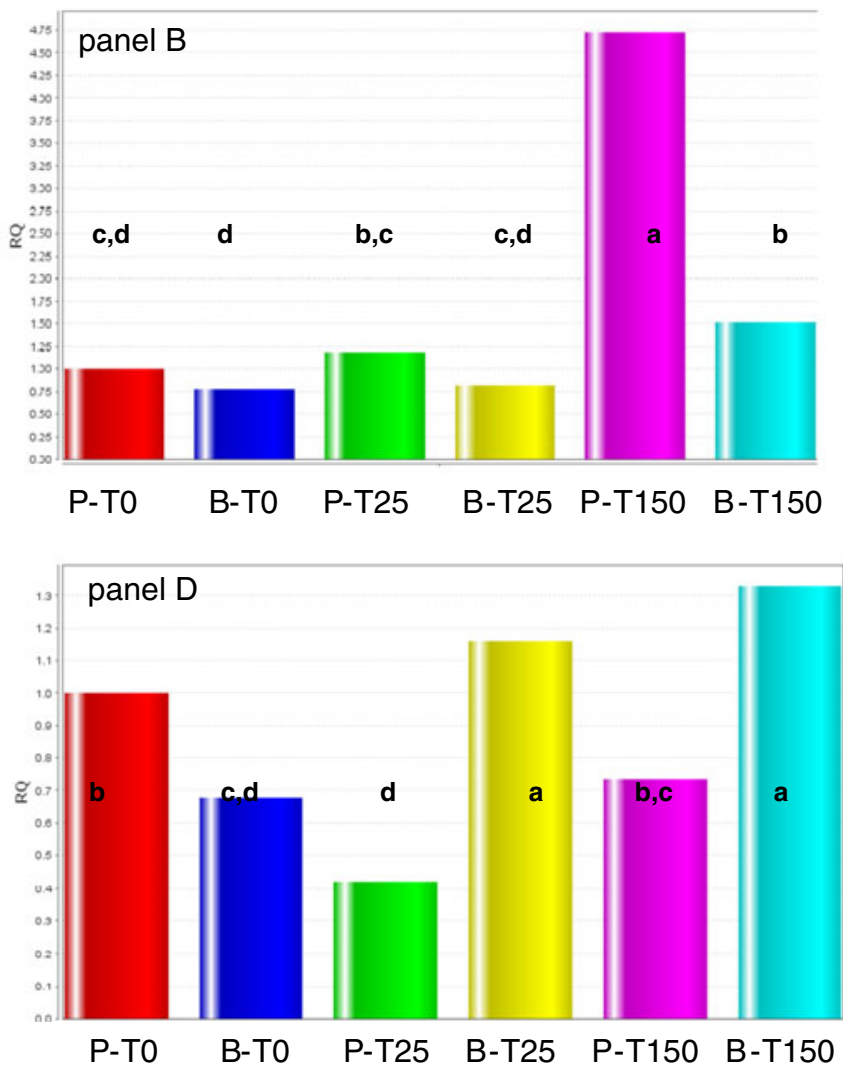

control $(B-T 0)$, Pérola under dehydration condition $(P-T 25)$, BAT477 dehydration condition $(B-T 25)$, Pérola under dehydration condition $(P$ T150), and BAT477 dehydration condition (B-T150). Letters shared in common between or among the groups would indicate no significant difference $(95 \%$ IC, $p<0.05)$ 
during that stage. The results of the present study corroborate that observation because a larger number of responsive genes were identified in the genotypes subjected to drought during the flowering stage $(67 \%)$ compared to the upregulated transcripts identified in the grain-filling stage (40\%).

For the experiment conducted in the greenhouse, the drought did not significantly modify the time of flowering, grain-filling, and even the maturity stage between the contrasting genotypes. As related by Lizana et al. (2006), even genotypes of common beans with different growth habit did not change significantly the time of flowering under drought stress. The advance in the physiological stages and in the harvesting time was observed in the genotypes under drought stress compared to the well-watered experimental conditions (data not shown). Early maturing in cultivated crop has proved more useful in dry environments because of their ability to escape the drought period (Beebe et al. 2013). In the present study, the contrasting genotypes showed the same ability under drought stress.

Drought is a multidimensional stress affecting plants at various levels of their organization, and the mechanisms of plant adaptation to this stress is one of the most complex biological processes. Several physiological traits associated with adaptation and/or adjustment to drought are determined in leaves such as the stomata distribution on leaves, transpiration rate, photosynthesis, and leaf area Rosales et al. (2012a; b) suggested mechanisms of the drought-resistant cultivars that rely on an efficient $\mathrm{CO}_{2}$ diffusion in leaf tissues and fixation, an efficient carbon mobilization from leaves to pods and/or seeds to maintain grain yield, a modulation in the stomatal closure by increasing the water use efficiency, and avoidance of ROS accumulation. The identification of differentially expressed genes under drought conditions has been the first step in understanding the stress response mechanisms in the common bean (Bray 1993; Kavar et al. 2008). These advances have been important for plant improvement programs worldwide (Deokar et al. 2011) toward the identification of molecular mechanisms that are potential targets in leaves which may help in the selection and development of superior genotypes under hydric stress conditions. For example, resistance to abiotic stresses has been demonstrated in a variety of crops through genetic manipulation of TFs and antioxidant proteins (Bhatnagar-Mathur et al. 2008; Vicuna et al. 2011).

The four cDNA libraries constituted a genetic sample that was representative of the two plant genotypes and their developmental stages, as demonstrated by the high number of redundant sequences ( $\geq 5$ reads; $63 \%$ ), which was almost twice as high as the number of unique sequences (37\%); this level of efficiency is needed to ensure that differentially expressed sequences are represented, which might be used to suggest profiles of expression in silico (Yu et al. 2003). The identification of responsive genes by the subtraction library strategy was previously demonstrated (Zhou et al. 2011; Abid et al. 2012). In the common bean, Kavar et al. (2008) identified 32 differentially expressed genes in eight genotypes of diverse origins and from different gene pools of the common bean; $18.75 \%$ of those sequences shared similar functions with the 67 contigs identified in the present study. Similarly, from the 277 sequences induced under drought stress that were reported by Seki et al. (2002), $22.4 \%$ exhibited similarity with the contigs recorded in the present study. These findings indicate that the mechanisms involved in drought responses are potentially common among plant species. This commonality might facilitate the elucidation of metabolic processes involved in the responses of $P$. vulgaris to drought.

As previously reported by Morais Júnior et al. (2008), the lower values of $\Psi_{\mathrm{f}}$ and $T_{\mathrm{f}}$ that were found in BAT 477 under drought conditions indicated the ability of that genotype to develop a stronger water potential gradient in the leaf-root system, greater water flow, more transpiration, and a lower leaf temperature compared to the Pérola genotype. Therefore, an individual analysis of the genes found in those genotypes is relevant to the identification of genes that are potentially associated with greater water usage efficiency (Rabello et al. 2008; Jiang et al. 2012; Chen et al. 2013). Overall, $65 \%$ of the sequences identified in the tolerant genotype during the flowering stage were related to genes expressed during the stress response, whereas that number decreased to $41 \%$ during the grain-filing stage. To identify genes that may be relevant for common bean drought tolerance, we focused on genes showing differences in the expression patterns in the tolerant compared to the sensitive genotype. The main identified gene products included PSII proteins, ARPs, HIR proteins, ribosomal machinery genes, proteins with zinc finger domains, and proteins associated with the oxidative stress response.

The transcripts identified in the tolerant genotype BAT 477- $F$ include the calmodulin 24-like protein, which is characterized as a $\mathrm{Ca}^{2+}$ receptor signaling complex. The activated $\mathrm{Ca}^{2+}$-calmodulin complex modulates the activity of several target stress-responsive proteins, because the $\mathrm{Ca}^{2+}$ influx into the cytoplasm acts as a signal transduction mediator, resulting in cell alterations that trigger event cascades related to physiological and developmental responses (van der Luit et al. 1999; Yang et al. 2010). In addition, we identified the nodulin 26 transcript. Nodulin 26 belongs to a family of major intrinsic proteins (MIPs) that are involved in the transport of several noncharged solutes including water, ammonia, and glycerol, and it possesses aquaporin activity (Wallace et al. 2006). These channels are involved in water transport dynamics, particularly under limiting conditions, and they play an important role in the protection against drought and the promotion of osmoregulation. The first characterized plant MIP was soybean nodulin 26 (Miao et al. 1992). This protein is abundant in the nodule membranes and facilitates the transport of compounds between plant cells and the compartments that 
contain nitrogen fixation microorganisms (Mullet and Whitsitt 1996).

Auxin is a plant growth regulator that is mainly produced at the apical buds, where it plays a key role in a wide variety of growth and developmental processes, such as lateral root formation, apical dominance, tropism, and vascular tissue differentiation. The ARPs are encoded by a large gene family and a recent study has showed their additive effect on the growth suppression (Lee et al. 2013). The ARPs are induced during drought, cold, and salt stresses and thus might also be related to water stress, as the mechanisms of response to these three types of stress are quite similar (Liu et al. 2013). The ARP TFs were upregulated in both genotypes in leaves and roots under hydric stress in this study. Several plant organs share common genetic control mechanisms (Dignat et al. 2013), and the ARP gene identified here is evidence of its action in important pathways activated under drought. Mantri et al. (2007) reported the induction/repression of ARP gene in several tissues including flowers, leaves, and roots of both susceptible and tolerant genotypes of cultivated chickpea. In the present study, despite ARP has been identified in the tolerant genotype (flowering stage), the upregulation of this gene in leaves under drought stress, which was highest in the susceptible genotype, is in accordance with the findings of Rosales et al. (2012b), which showed that upon drought, common bean genotypes showed a biomass reduction compared to well-watered plants. As the validation reverse transcription qPCR experiment tested the same samples under different experimental conditions (vegetative stage) used for the libraries construction, the increased expression in the susceptible genotype that could be explained as the genetic control of drought tolerance is extremely complex. This mechanism suggests that at the reproductive stage, under drought, an effective remobilization of the available photosynthates is a priority to develop grains (Rosales-Serna et al. 2004), and a tolerant plant is more effective in doing so because it requires a smaller reduction of the leaf area. In roots, the level of expression of ARP of the control plants was higher than in leaves subjected to stress. However, this gene was substantially upregulated in both genotypes under drought stress, indicating an activation of the mechanism of root development to improve soil moisture extraction.

The overexpressed HIR proteins in the tolerant genotype are involved in cellular hypersensitivity reactions and belong to the proliferation, ion, and death (PID) superfamily, which participates in cell proliferation, ion-channel regulation, and cell death (Nadimpalli et al. 2000). HIR proteins are overexpressed in the foliar tissues of plants during the development of lesions (Xiao et al. 2001). The HIR-induced cell death mechanisms are accompanied by increased hydrogen peroxide $\left(\mathrm{H}_{2} \mathrm{O}_{2}\right)$ levels and pathogen defenses. According to Jung et al. (2008), HIR was expressed in peppers that were subjected to drought-induced osmotic stress; however, few data have been reported on the role of HIR proteins in the responses to several biotic and abiotic stressors. Many ESTs similar to ribosomal machinery genes were upregulated in tolerant genotype BAT 477-GF, such as the $40 \mathrm{~S}$ ribosomal protein $\mathrm{S} 16$, which might be involved in the connection between drought sensitivity and the mechanisms of differential regulation and protein synthesis (Benešová et al. 2012).

The tolerant genotype BAT 477 also had more upregulated zinc finger protein genes than Pérola did. These are an important class of TFs encoded by diverse genes in eukaryotes (Yoshioka et al. 2001). They play roles in plant defenses, stress responses (Kam et al. 2008), and flower development and morphogenesis (Kim et al. 2004). In the present study, the zinc finger C3HC4-type (RING finger) TF was identified in BAT 477-GF, whereas the $\mathrm{C} 2 \mathrm{H} 2$ zinc finger was identified in Pérola-F. This family of TFs affects the expression of ABA mutant genes in rice plants subjected to dehydration (Oh et al. 2005). In Arabidopsis, gene expression analysis of ZFP is sensitive to drought stress (Seki et al. 2002; Kam et al. 2008). Additionally, a study by Li et al. (2010) showed that two $\mathrm{C} 2 \mathrm{H} 2$ zinc finger proteins in cotton plants are involved in the drought stress response and ABA signaling. Because ABA is involved in stress responses, a more detailed investigation of the ZFP family TFs that were identified in the present study will be performed first to verify the relationship between ZFP upregulation and drought tolerance, then to develop strategies to characterize this ZFP gene family for the development of markers for assisted selection, and finally to develop genetically modified genotypes of the common bean that can overexpress this gene.

Although different, some of the overexpressed genes in the tolerant and susceptible genotypes act in metabolic pathways and share mechanisms of action in drought tolerance responses. Among such genes are those that encode enzymes involved in the detoxification of reactive oxygen species (ROS), specifically those that promote cell protection against oxidative stress (Rabello et al. 2008; Torres and Dangl 2005). According to Bray (2007), it is difficult to establish whether these genes are induced to repair the damage caused directly by drought or whether the proteins accumulate to correct the damage caused by a secondary stress. The main putative proteins found in the present study that act in the oxidative stress response were NADPH quinone oxidoreductase-like protein, which was found in the susceptible genotype Pérola-F, as well as NAD-dependent isocitrate dehydrogenase and NADH-ubiquinone oxidoreductase-like protein, which were both found in the tolerant genotype.

Genes that were already known to participate in the drought response were found in Pérola during the flowering stage. Additionally, the overexpression of a gene under stress conditions does not guarantee that its product will strengthen the ability of the plant to overcome the stressor, which is due to 
post-transcriptional control and regulation mechanisms (Day and Tuite 1998) that might have different effects in the susceptible and tolerant genotypes. Increased expression of genes induced by water deficit in Pérola compared to BAT477 might suggest that these genes are involved in genetic mechanisms that do not act independently contributing to increased drought tolerance in common beans, but rather act as parts of gene regulatory networks that could be activated conferring the drought tolerance. As more genes related to drought tolerance are identified, additional complex networks will be elucidatet allowing the identification of key points for developing strategies for genetic breeding of drought tolerance. Such genes identified in the susceptible genotype and previously related to drought response encode protein kinases, chaperones, and TFs as ethylene-responsive factors (ERFs), and the dehydration-responsive element binding (DREB). Several author have shown that TFs, as ERFs, and DREB play a vital role in the regulation of gene expression and are involved in various biological processes such as flower and seed development (Athanasios et al. 2012), fruit maturation (Chung et al. 2010), pathogen defense (Liebrand et al. 2012), and stress responses (Chen et al. 2012; Li et al. 2013). The protein kinases are known to be involved in various signaling cascades related to stress responses (Xiong et al. 2002). Thus, the predominance of transcripts of these signaling molecules in tolerant genotypes may have significance and needs further investigation.

Drought affects the carbon balance of plants and thus affects normal photosynthesis and respiration (Tezara et al. 1999; Galle et al. 2010). As related by Le at al. (2012), the regulation of many photosynthesis-related genes in soybean, which is related with the growth rate under drought stress, may serve as an adaptive mechanism for plant survival. PSII is considered the most sensitive component of the photosynthetic system during the activation of response mechanisms to environmental disturbances, and the study of various protein components of PS2 might reveal stress response mechanisms in plants (Pieters and Souki 2005). Dehydrated leaves lose a substantial portion of their photosynthetic ability, and the combined stresses of drought and high temperature cause a remarkable reduction of the photosynthetic capability of plants. In the present study, several genes related to PSII were identified in the two investigated genotypes during both the flowering and grain-filling stages. The levels of gene expression in the tolerant and susceptible genotypes will be subjected to a comparative analysis to establish whether their differences can account for the effective activities of those proteins in the $P$. vulgaris drought tolerance response aiming to be exploited as traits for selection.

According to the GO terms, $48 \%$ of the sequences were associated with cell metabolism. The sequences in that category were associated with gene products that support the processes of molecular synthesis and degradation, as well as those that allow for cell growth and development by adjusting responses to the environment. Thus, many of these gene products were related to drought responses such that the cells might avoid or tolerate stress. As flowering is one of the most important agronomic traits influencing crop yield, the analysis of its molecular control is an important step toward the understanding of the genetic mechanisms underlying this trait (Jung et al. 2013). This knowledge is critical for the breeding of crop varieties more tolerant to drought stress. Recently, Teaster at al. (2012) concluded that the early flowering phenotype of Arabidopsis overexpressing a fatty acid amide hydrolase (FAAH) is, in part, explained by the increase of the expression of a gene related to flowering, and was a result of the increase of the bioactive lipid (N-acylethanolamine) terminated by the hydrolytic activity of FAAH. In the present study, the abundance of genes categorized as hydrolase activity and biosynthetic pathways for the production of fatty acids may play an important function in floral signaling pathways in the tolerant genotype, as described by Teaster et al. (2012).

The phases of seed development have been well established for some legumes (Weber et al. 2005) and, more recently, significant advances are being achieved in understanding the genetic mechanisms of pathways related to seed development (Abid et al. 2012; Jones and Vodkin 2013). In the present study, it was observed that the tolerant genotype responded to drought stress modulating different set of genes during the grain-filling stage; in addition, many subcategories related to metabolic processes, carbohydrate and secondary metabolic processes were identified. As the main reserve substances in seeds are compounds derived from carbon fixation, as carbohydrates, the higher expression of genes present in photosynthetic routes in the tolerant genotypes induced by water deficit may be responsible of the higher yield stability observed.

The research presented here provides the first and significant insight into our understanding of molecular process in reproductive stages and also provide an important resource for the scientific community interested in the molecular genetics and functional genomics of $P$. vulgaris. Moreover, despite the fact that over 150,000 P. vulgaris ESTs have already been deposited in the GenBank, approximately $98 \%$ of the EST described in this research are not represented in the public database. In this study, we are making these new EST derived from flowering and grain-filling stages under drought stress public to be freely used for the legume scientific community. The results of BLAST2GO analysis showed that $41 \%$ of the expressed sequences from the common bean exhibited similarity with soybean ( $G$. $\max$ ), which is a leguminous plant that is phylogenetically close to $P$. vulgaris. Both species belong to the tribe Phaseoleae, had a common ancestor as recently as 20 million years ago, and share large syntenic regions (McClean et al. 2010). Information from the sequencing of the soybean genome (Schmutz et al. 2010) and the more recent sequencing of two varieties of common bean will facilitate 
the integration of data into the structural and functional genome, which will benefit the study of both G. $\max$ and $P$. vulgaris. Overall, $24 \%$ of the exclusive contigs were associated with gene products of unknown function. Therefore, further studies are needed before biological functions can be attributed to these gene products, which might play important roles in the adaptation of drought-exposed plants (Rabello et al. 2008).

The strategy to identify differentially expressed genes in plants under drought conditions through the development of subtraction libraries proved effective and indicated some genes that might be explored by genetic improvement programs during searches for allelic variants in germplasm banks from this species, as well as genes that represent potential targets for studies of gene overexpression in the common bean by genetic modification. Our qPCR analysis of some of the most commonly expressed genes in the libraries validated the fact that the subtracted genes were indeed the most commonly expressed in the genotypes in which they were identified. In the present study, the transcripts that were identified as related to drought responses in the common bean add to the growing public dataset of genes enriched under drought conditions and might be used to more thoroughly investigate the molecular basis of the drought response in the common bean. In a practical and applicable way, through alignment of the identified genes with the reference genomes, many polymorphic markers in linkage disequilibrium with the target genes may be identified, providing molecular tools to be used in association studies by exploiting the historical recombination between loci in genetic diversity panels and to examine gene expression with greater genetic resolution. In this way, it will be possible to generate functional information on genes and identify the genetic variations that cause trait variation, adding to our understanding of the genetic control of quantitative traits that has so far been obtained mainly by breeding programs.

Acknowledgments We thank the National Council for Scientific and Technological Development (CNPq) for the grants to MP, GJPJr, CB, and RPV-B; the Coordination of Improvement of Higher-Education Personnel/ Ministry of Education (CAPES/MEC) for the grants to BSFM, RDDS, and PFZC; the Minas Gerais State Research Foundation (Fapemig) for the grant to TS; and the Brazilian Enterprise for Agricultural Research (Embrapa MP2) for financial support for this research.

\section{References}

Abid G, Sassi K, Muhovski Y, Jacquemin J-M, Mingeot D, Tarchoun H, Baudoi J-P (2012) Identification and analysis of differentially expressed genes during seed development using suppression subtractive hybridization (SSH) in Phaseolus vulgaris. Plant Mol Biol Rep 30:719-730. doi:10.1007/s11105-011-0381-7

Altschul SF, Madden TL, Schäffer AA, Zhang J, Zhang Z, Miller W, Lipman DJ (1997) Gapped BLAST and PSI-BLAST : a new generation of protein database search programs. Nucleic Acids Res 25:3389-3402

Asfaw A (2011) Breeding for drought tolerance by integrative design: the case of common bean (Phaseolus vulgaris L.) in Ethiopia. Ph.D. thesis, Wageningen University

Athanasios ST, Konstantinos P, Panagiotis M, Anagnostis A (2012) Sequence characterization and expression analysis of three APETALA2-like genes from saffron crocus. Plant Mol Biol Rep 30:443-452

Atkinson NJ, Urwin PE (2012) The interaction of plant biotic and abiotic stresses: from genes to the field. J Exp Bot 63(10):3523-3543. doi: $10.1093 / \mathrm{jxb} / \mathrm{ers} 100$

Beebe SE, Rao IM, Blair MW, Acosta-Gallegos JA (2013) Phenotyping common beans for adaptation to drought. Front Physiol 4:35. doi:10. 3389/fphys.2013.00035

Benešová M, Holá D, Fischer L, Jedelský PL, Hnilička F, Wilhelmová N, Rothová O et al (2012) The physiology and proteomics of drought tolerance in maize: early stomatal closure as a cause of lower tolerance to short-term dehydration. PloS One 7(6):e38017

Bhatnagar-Mathur P, Vadez V, Sharma KK (2008) Transgenic approaches for abiotic stress tolerance in plants: retrospect and prospects. Plant Cell Rep 27:411-424

Blair MW, Fernandez AC, Pedraza F, Muñoz-Torres MC, Kapu NS, Brown K, Lynch JP (2011a) Parallel sequencing of expressed sequence tags from two complementary DNA libraries for high and low phosphorus adaptation in common beans. Plant Genome 4(3): 204-217

Blair MW, Fernandez AC, Ishitani M, Moreta D, Seki M, Ayling S (2011b) Construction and EST sequencing of full-length, drought stress cDNA libraries for common beans (Phaseolus vulgaris L.). BMC Plant Biol 11(1):171

Bray EA (1993) Molecular responses to water deficit. Plant Physiol 103: $1035-1040$

Bray EA (2007) Plant response to water-deficit stress. University of Chicago, Chicago, IL. doi:10.1002/9780470015902.a0001298.pub2

Brondani RPV, Brondani C, Grattapaglia D (2007) Manual prático para o desenvolvimento de marcadores microssatélites em plantas. Embrapa Informação Tecnológica, Brasília

Chen N, Yang QL, Su MW, Pan LJ, Chi XY, Chen MN, He YN, Yang Z, Wang T, Wang M, Yu SL (2012) Cloning of six ERF family transcription factor genes from peanut and analysis of their expression during abiotic stress. Plant Mol Biol Rep 30:1415-1425

Chen J, Song Y, Zhang H, Zhang D (2013) Genome-wide analysis of gene expression in response to drought stress in Populus simonii. Plant Mol Biol Rep 31:946-962. doi:10.1007/s11105-013-0563-6

Chomczynski P, Sacchi N (1987) Single-step method of RNA isolation by acid guanidinium thiocyanate-phenol-chloroform extraction. Anal Biochem 162(1):156-159

Chung M-Y, Vrebalov J, Alba R, Lee J, McQuinn R, Chung J-D, Klein P, Giovannoni J (2010) A tomato (Solanum lycopersicum) APETALA2/ ERF gene, SIAP2a, is a negative regulator of fruit ripening. Plant J 64: 936-939

Conesa A, Götz S, García-Gómez JM, Terol J, Talón M, Robles M (2005) Blast2GO: a universal tool for annotation, visualization and analysis in functional genomics research. Bioinformatics 21(18):3674-3676

Day DA, Tuite MF (1998) Post-transcriptional gene regulatory mechanisms in eukaryotes: an overview. J Endocrinol 157(3):361-371

Deokar AA, Kondawar V, Jain PK, Karuppayil SM, Raju NL, Vadez V, Varshney RK, Srinivasan R (2011) Comparative analysis of expressed sequence tags (ESTs) between drought-tolerant and -susceptible genotypes of chickpea under terminal drought stress. BMC Plant Biol 11(1):70

Diatchenko L, Lau YF, Campbell AP, Chenchik A, Moqadam F, Huang B, Lukyanov S, Lukyanov K, Gurskaya N, Sverdlov ED, Siebert PD (1996) Suppression subtractive hybridization: a method for generating differentially regulated or tissue-specific cDNA probes and libraries. Proc Natl Acad Sci U S A 93:6025-6030 
Dignat G, Welcker C, Sawkins M, Jm R, Tardie F (2013) The growths of leaves, shoots, roots and reproductive organs partly share their genetic control in maize plants. Plant Cell Environ 36:1105-1111

Emam Y, Shekoofa A, Salehi F, Jalali AH (2010) Water stress effects on two common bean cultivars with contrasting growth habits. Am-Eur J Agric Environ Sci 9(5):495-499

Ewing B, Hillier L, Wendl MC, Green P (1998) Base-calling of automated sequencer traces using phred: I. Accuracy assessment. Genome Res 8(3): 175-185

Fageria NK, Baligar VC, Jones CA (1991) Common bean and cowpea. Growth and mineral nutrition of field crops. Marcel Dekker, New York, pp 280-318

FAO (2012) World water day 2012: water and food security. FAO water. http://www.fao.org/nr/water/news/wwd12.html. Accessed 08 February 2013

Galle A, Florez-Sarasa I, Thameur A, Paepe R, Flexas J, Ribas-Carbo M (2010) Effects of drought stress and subsequent rewatering on photosynthetic and respiratory pathways in Nicotiana sylvestris wild type and the mitochondrial complex I-deficient CMSII mutant. J Exp Bot 61(3):765-775

Gonçalves RJS, Abreu AFB, Ramalho MAP, Bruzi AT (2009) Strategies for recommendation of common bean lines tested for value of cultivation and use in different environments. Crop Breed Appl Biotechnol 9:132-139

Graham MA, Blanco-Lo L, Silvente S, Medrano-Soto A, Blair MW, Herna G, Vance CP, Lara M (2005) Sequencing and analysis of common bean ESTs. Building a foundation for functional genomics. Plant Physiol 137(4):1211-1227

Guimarães CM, Zimmermann MJ, Rocha M, Yamada T (1988) Efeitos fisiológicos do estresse hídrico. Cultura do feijoeiro: fatores que afetam a produtividade. Associação Brasileira para Pesquisa da Potassa e do Fosfato, Piracicaba, pp 157-174

Guimarães CM, Stone LF, Moreira JAA (2002) Compactação do solo na cultura do feijoeiro: II. efeito sobre o desenvolvimento radicular e da parte aérea. R Bras Eng Agric Ambiental 6(2):213-218

Harb A, Krishnan A, Ambavaram MMR, Pereira A (2010) Molecular and physiological analysis of drought stress in Arabidopsis reveals early responses leading to acclimation in plant growth. Plant Physiol 154(3):1254-1271

Hellemans J, Mortier G, Paepe A, Speleman F, Vandesompele J (2007) qBase relative quantification framework and software for management and automated analysis of real-time quantitative PCR data. Genome Biol 8(2):R19

Jiang T, Fountain J, Davis G, Kemerait R, Scully B, Lee RD, Guo B (2012) Root morphology and gene expression analysis in response to drought stress in maize (Zea mays). Plant Mol Biol Rep 30:360-369

Jones SI, Vodkin LO (2013) Using RNA-Seq to profile soybean seed development from fertilization to maturity. PLoS One 8(3):e59270. doi:10.1371/journal.pone.0059270

Jung HW, Lim CW, Lee SC, Choi HW, Hwang CH, Hwang BK (2008) Distinct roles of the pepper hypersensitive induced reaction protein gene CaHIR1 in disease and osmotic stress, as determined by comparative transcriptome and proteome analyses. Planta 227(2): 409-425

Jung C-H, Wong CR, Singh MB, Bhalla PL (2013) Comparative genomic analysis of soybean flowering genes. PLoS One 7:e38250

Kakumanu A, Ambavaram MMR, Klumas C, Krishnan A, Batlang U, Myers E, Grene R, Pereira A (2012) Effects of drought on gene expression in maize reproductive and leaf meristem tissue revealed by RNA-Seq. Plant Physiol 160(2):846-867

Kalavacharla V, Liu Z, Meyers BC, Thimmapuram J, Melmaiee K (2011) Identification and analysis of common bean (Phaseolus vulgaris L.) transcriptomes by massively parallel pyrosequencing. BMC Plant Biol 11(1): 135

Kam J, Gresshoff PM, Shorter R, Xue GP (2008) The Q-type C2H2 zinc finger subfamily of transcription factors in Triticum aestivum is predominantly expressed in roots and enriched with members containing an EAR repressor motif and responsive to drought stress. Plant Mol Biol 67(3):305-322

Kavar T, Maras M, Kidric M, Šuštar-Vozlic J, Meglic V (2008) Identification of genes involved in the response of leaves of Phaseolus vulgaris to drought stress. Mol Breed 21:159-172

Kim SH, Hong JK, Lee SC, Sohn KH, Jung HW (2004) CAZFP1, Cys 2/ His 2-type zinc-finger transcription factor gene functionsas a pathogen-induced early-defense gene in Capsicum annuum. Plant Mol Biol 55:883-904

Lacerda CF, Carvalho CM, Vieira MR, Nobre JGA, Neves ALR, Rodrigues CF (2010) Análise de crescimento de milho e feijão sob diferentes condições de sombreamento. R Bras Ciências Agrár 5(1): $18-24$

Le DT, Nishiyama R, Watanabe Y, Tanaka M, Seki M, Ham LH, Yamaguchi-Shinozaki K, Shinozaki K, Tran L-SP (2012) Differential gene expression in soybean leaf tissues at late developmental stages under drought stress revealed by genome-wide transcriptome analysis. PLoS One 7:e49522

Lee J, Han CT, Hur Y (2013) Molecular characterization of the Brassica rapa auxin-repressed, superfamily genes, BrARP1 and BrDRM1. Mol Biol Rep 40(1):197-209

Li G, Tai FJ, Zheng Y, Luo J, Gong SY, Zhang ZT, Li XB (2010) Two cotton Cys2/His2-type zinc-finger proteins, GhDi19-1 and GhDi192 , are involved in plant response to salt/drought stress and abscisic acid signaling. Plant Mol Biol 74(4-5):437-452

Li M-Y, Wang F, Jiang Q, Li R, Ma J, Xiong A-S (2013) Genome-wide analysis of the distribution of AP2/ERF transcription factors reveals duplication and elucidates their potential function in Chinese cabbage (Brassica rapa ssp. pekinensis). Plant Mol Biol Rep 31:10021011. doi:10.1007/s11105-013-0570-7

Liebrand TWH, Smit P, Abd-El-Haliem A, Jonge R, Cordewener JHG, America AHP, Sklenar J, Jones AME, Robatzek S, Thomma BPHJ, Tameling WIL, Joosten MHAJ (2012) Endoplasmic reticulumquality control chaperones facilitate the biogenesis of $\mathrm{Cf}$ receptorlike proteins involved in pathogen resistance of tomato. Plant Physiol 159:1819-1833

Lisitsyn N, Lisitsyn N, Wigler M (1993) Cloning the differences between two complex genomes. Science 259:946-951

Liu M, Shi J, Lu C (2013) Identification of stress-responsive genes in Ammopiptanthus mongolicus using EST generated from cold- and drought-stressed seedlings. BMC Plant Biol 13:88

Lizana C, Wentworth M, Martinez JP, Villegas D, Meneses R, Murchie EH, Pastenes C et al (2006) Differential adaptation of two varieties of common bean to abiotic stress: I. Effects of drought on yield and photosynthesis. J Exp Bot 57(3): 685-697

Mantri NL, Ford R, Coram TE, Pang ECK (2007) Trascriptional profiling of chickpea genes differentially regulated in response to highsalinity, cold and drought. BMC Genomics 8:303

Martins PK, Jordão BQ, Yamanaka N, Farias JRB, Beneventi MA, Binneck E, Fuganti R, Stolf R, Nepomuceno AL (2008) Differential gene expression and mitotic cell analysis of the drought tolerant soybean (Glycine $\max$ L. Merrill Fabales, Fabaceae) Cultivar MG/BR46 (Conquista) under two water deficit induction systems. Genet Mol Biol 31(2): 512-521

McClean PE, Mamidi S, McConnell M, Chikara S, Lee R (2010) Synteny mapping between common bean and soybean reveals extensive blocks of shared loci. BMC Genomics 18(11):184

Miao GH, Hong Z, Verma DP (1992) Topology and phosphorylation of soybean Nodulin-26, an intrinsic protein of the peribacteroid membrane. J Cell Biol 118(2):481-490

Miklas PN, Kelly JD, Beebe SD, Blair MW (2006) Common bean breeding for resistance against biotic and abiotic stresses: from classical to MAS breeding. Euphytica 147:105-131 
Morais Júnior OP, Menezes J, Silva SI, Silva ACL, Stone LF, Guimarães CM (2008) Ajustamento hídrico do feijoeiro em condições de seca. Documentos, IAC, Campinas 85(62):1129-1132

Mullet JE, Whitsitt MS (1996) Plant cellular responses to water deficit. Plant Growth Regul 20(2): 119-124 http://link.springer.com/ journal/10725

Nadimpalli R, Yalpani N, Johal GS, Simmons CR (2000) Prohibitins, stomatins, and plant disease response genes compose a protein superfamily that controls cell proliferation, ion channel regulation, and death. J Biol Chem 275(38):29579-29586

Nagalakshmi U, Waern K, Snyder M (2010) RNA-Seq: a method for comprehensive transcriptome analysis, chap 4. Curr Protoc Mol Biol. Unit 4.11.1-13

Nunez-Barrios A (1991) Effects of soil water deficits on dry beans (Phaseolus vulgaris L.) at different growing stages. Ph.D. thesis, Michigan State University

Oh SJ, Song SI, Kim YS, Jang HJ, Kim SY, Kim M, Kim YK, Nahm BH, Kim JK (2005) Arabidopsis CBF3/DREB1A and ABF3 in transgenic rice increased tolerance to abiotic stress without stunting growth. Plant Physiol 138(1):341-351

Pappas GJ Jr, Miranda RP, Martins NF, Togawa RC, Costa MMC (2008) SisGen: a CORBA-based data management program for DNA sequencing projects. Lect Notes Comput Sci 5109:116-123

Pastorian K, Hawel L, Byus CV (2000) Optimization of cDNA representational difference analysis for the identification of differentially expressed mrnas. Anal Biochem 283(1):89-98, July 15

Pérez-Rodríguez P, Riaño-Pachón DM, Corrêa LG, Rensing SA, Kersten B, Mueller-Roeber B (2010) PlnTFDB: updated content and new features of the plant transcription factor database. Nucleic Acids Res 38(Database issue):D822-D827

Pertea G, Huang X, Liang F, Antonescu V, Sultana R, Karamycheva S, Lee Y, White J, Cheung F, Parvizi B, Tsai J, Quackenbush J (2003) TIGR gene indices clustering tools (TGICL): a software system for fast clustering of large EST datasets. Bioinformatics 19(5):651-652

Pieters A, Souki SE (2005) Effects of drought during grain filling on PSII activity in rice. J Plant Physiol 162:903-911

Prabu G, Kawar PG, Pagariya MC, Prasad DT (2011) Identification of water deficit stress upregulated genes in sugarcane. Plant Mol Biol Rep 29:291-304

Rabello AR, Guimarães CM, Rangel PH, da Silva FR, Seixas D, de Souza E, Brasileiro AC, Spehar CR, Ferreira ME, Mehta A (2008) Identification of drought-responsive genes in roots of upland rice (Oryza sativa L.). BMC Genomics 9:485

Rosales MA, Cuellar-Ortiz SM, de la Paz A-MM, Acosta-Gallegos J, Covarrubias AA (2012a) Physiological traits related to terminal drought resistance in common bean (Phaseolus vulgaris L.). J Sci Food Agric 93(2):324-331

Rosales MA, Ocampo E, Rodríguez-Valentín R, Olvera-Carrillo Y, AcostaGallegos J, Covarrubias AA (2012b) Physiological analysis of common bean (Phaseolus vulgaris L.) cultivars uncovers characteristics related to terminal drought resistance. Plant Physiol Biochem 56:24-34

Rosales-Serna R, Kohashi-Shibata J, Acosta-Gallegos JA, Trejo-López C, Ortiz-Cereceres J, Kelly JD (2004) Biomass distribution, maturity acceleration and yield in drought-stressed common bean cultivars. Field Crops Res 85(2-3):203-211

Schena M, Shalon D, Davis RW, Brown PO (1995) Quantitative monitoring of gene expression patterns with a complementary DNA microarray. Science 270:467-470

Schmutz J, Cannon SB, Schlueter J, Ma J, Mitros T, Nelson W, Hyten DL et al (2010) Genome sequence of the palaeopolyploid soybean. Nature 463(7278):178-183
Seki M, Narusaka M, Ishida J, Nanjo T, Fujita M, Oono Y, Kamiya A et al (2002) Monitoring the expression profiles of 7000 Arabidopsis genes under drought, cold and high-salinity stresses using a fulllength cDNA microarray. Plant J 31(3):279-292

Serraj R, Krishnamurthy L, Kashiwagi J, Kumar J, Chandra S, Crouch JH (2004) Variation in root traits of chick pea (Cicer arietinum L.) grown under terminal drought. Field Crops Res 88:115-127

Szilagyi L (2003) Influence of drought on seed components in common bean. Bulg J Plant Physiol Special Issue:320-330

Teaster ND, Keereetaweep J, Kilaru A, Wang Y-S, Tang Y, Tran CN-Q, Ayre BG, Chapman KD, Blancaflor EB (2012) Overexpression of fatty acid amide hydrolase induces early flowering in Arabidopsis thaliana. Front Plant Sci 3:32. doi:10.3389/fpls.2012.00032

Terán H, Singh SP (2002) Comparison of sources and lines selected for drought resistance in common bean. Crop Sci 42:64-70

Tezara W, Mitchell VJ, Driscoll SD, Lawlor DW (1999) Water stress inhibits plant photosynthesis by decreasing coupling factor and ATP. Nature 401:914-917

Thompson JD, Higgins DG, Gibson TJ (1994) CLUSTAL W: improving the sensitivity of progressive multiple sequence alignment through sequence weighting, position-specific gap penalties and weight matrix choice. Nucleic Acids Res 22:4673-4680

Tian J, Venkatachalam P, Liao H, Yan X, Raghothama K (2007) Molecular cloning and characterization of phosphorus starvation responsive genes in common bean (Phaseolus vulgaris L.). Planta 227(1):151-165

Torres MA, Dangl JL (2005) Functions of the respiratory burst oxidase in biotic interactions, abiotic stress and development. Curr Opin Plant Biol 8(4):397-403

van der Luit AH, Olivari C, Haley A, Knight MR, Trewavas AJ (1999) Distinct Calcium Signaling Pathways Regulate Calmodulin Gene Expression in Tobacco. Plant Physiol 121:705-714

Velculescu VE, Zhang L, Vogelstein B, Kinzler KW (1995) Serial analysis of gene expression. Science 270(5235):484-487

Vicuna D, Malone RP, Dix PJ (2011) Increased tolerance to abiotic stresses in tobacco plants expressing a barley cell wall peroxidase. J Plant Sci 6:1-13

Wallace IS, Choi WG, Roberts DM (2006) The structure, function and regulation of the nodulin 26-like intrinsic protein family of plant aquaglyceroporins. Biochim Biophys Acta 1758(8):1165-1175

Weber H, Borisjuk L, Wobus U (2005) Molecular physiology of legumes seed development. Annu Rev Plant Biol 56:253-279

Xiao F, Tang X, Zhou JM (2001) Expression of 35S:Pto globally activates defense-related genes in tomato plants. Plant Physiol 126(4): $1637-1645$

Xiong L, Schumaker K, Zhu J (2002) Cell signaling during cold, drought, and salt stress. Plant Cell Online 14:165-183

Yang L, Ji W, Zhu Y, Gao P, Li Y, Cai H, Bai X, Guo D (2010) GsCBRLK, a calcium/calmodulin-binding receptor-like kinase, is a positive regulator of plant tolerance to salt and ABA stress. J Exp Bot 61(9):2519-2533

Yoshioka K, Fukushima S, Yamazaki T, Yoshida M, Takatsuji H (2001) The plant zinc finger protein ZPT2-2 has a unique mode of DNA interaction. J Biol Chem 276(38):35802-35807

Yu J, Farjo R, MacNee SP, Baehr W, Stambolian DE, Swaroop A (2003) Annotation and analysis of 10,000 expressed sequence tags from developing mouse eye and adult retina. Genome Biol 4(10):R65

Zhou MB, Yang P, Gao PJ, Tang D (2011) Identification of differentially expressed sequence taqs in rapidly elongating Phyllostachys pubescens internodes by suppressive subtractive hybridization. Plant Mol Biol Rep 29:224-231 